\title{
Seasonal clutch size decline and individual variation in the timing of breeding are related to female body condition in a non-migratory species, the Upland Goose Chloephaga picta leucoptera
}

\author{
Anja Gladbach • David Joachim Gladbach • \\ Petra Quillfeldt
}

Received: 17 September 2009/Revised: 8 March 2010/Accepted: 15 March 2010/Published online: 2 April 2010

(C) The Author(s) 2010. This article is published with open access at Springerlink.com

\begin{abstract}
Several studies have shown that waterfowl females in good condition lay larger clutches and start egglaying earlier in a breeding season. However, most of these studies lack corresponding data on individual condition and timing of breeding in different years. We analysed data on clutch size, egg size, hatching date and female body condition of a non-migratory species, the Upland Goose Chloephaga picta leucoptera, recorded in three seasons on New Island, Falkand Islands. We found a strong seasonal decline in both egg and clutch size. Egg size increased with clutch size. The mean egg volume and total clutch volume increased with female body condition and hatching date was earlier for females in higher body condition. Chicks hatched from nests with higher mean egg volume had higher early body condition. We also compared individual females between different study years and found that individual body condition showed a significant repeatability between years, whereas hatching date did not. While female aging did not systematically affect hatching date, females produced clutches that hatched earlier in years of higher body condition. We could thus show for the first
\end{abstract}

Communicated by P. H. Becker.

Electronic supplementary material The online version of this article (doi:10.1007/s10336-010-0518-8) contains supplementary material, which is available to authorized users.

A. Gladbach $(\bowtie) \cdot$ P. Quillfeldt

Max Planck Institute for Ornithology, Vogelwarte Radolfzell, Schlossallee 2, 78315 Radolfzell, Germany

e-mail: anja.gladbach@gmx.de

D. J. Gladbach

Agroecology, Department of Crop Science,

University of Göttingen, Waldweg 26,

37073 Göttingen, Germany time that the frequently reported negative relationship between female condition and hatching date also holds true on an individual basis. To our knowledge, this is the first study on seasonal clutch size decline in sheldgeese and one of a few in waterfowl comparing condition and timing of breeding within individuals between different years.

Keywords Clutch size decline · Egg size ·

Chloephaga picta leucoptera - Reproductive investment . Body condition

\section{Introduction}

There are numerous studies on seasonal variation in reproductive success in birds, one of the most common patterns being a seasonal decline in clutch size (Klomp 1970). Early-nesting birds often lay bigger clutches, and their offspring grow more rapidly and have a higher chance of survival and recruitment than late-nesting birds (Blums et al. 2002; Drent and Daan 1980; Hochachka 1990; Sockman et al. 2006), which results in a decrease in offspring value within a season. In precocial birds such as waterfowl, young receive parental care in the form of vigilance, social support and defence against predators (e.g. Lamprecht 1985; Owen and Black 1990; Schindler and Lamprecht 1987; Winkler and Walters 1983). Parents also lead their offspring to good feeding sites and enable chicks to gain access to these sites when competitors are present (Lepage et al. 1999; Winkler and Walters 1983). However, chicks do not depend on parental feeding, a component that is correlated with clutch size in altricial species (Lack 1968). Instead, the investment into clutch formation plays an important role for precocial chick survival. Most hypotheses concerning clutch size in waterfowl have 
implied that the condition of the female prior to laying is a determinant for reproductive success (Bengston 1971; Johnsgard 1973; Lack 1968; Ryder 1970; Winkler and Walters 1983). The body condition of individuals can vary according to individual quality and experience, leading to increased foraging efficiency, as well as the food resources available in the territory. Thus, high-quality individuals in high-quality territories may gain condition more rapidly after the winter and would therefore be the first to start laying in the breeding season, while low quality individuals in lower quality territories or individuals facing less favourable feeding conditions would lay later (Rowe et al. 1994; Sockman et al. 2006). Drent and Daan (1980) suggested that the conflict between early breeding (high offspring value) and late breeding (higher accumulated condition and potential clutch size) results in the observed timing of laying and clutch size. From a graphical model, Drent and Daan (1980) concluded that birds in poorer condition might have more to gain from a delay than birds in good condition. Field studies have shown that in most species females in good condition lay larger clutches and lay earlier in the season (Klomp 1970; Sockman et al. 2006). Experiments manipulating parental condition by supplementary feeding prior to egg laying resulted in earlier laying and increased clutch sizes (Karell et al. 2008; Meijer et al. 1988, 1990; Rowe et al. 1994).

However, most of the studies on the relationship between body condition and hatching date have been conducted either using data on population-level (e.g. Bety et al. 2003; Dalhaug et al. 1996; Devries et al. 2008; Sjoberg 1994) or, if conducted on an individual basis, then only on repeated observations of clutch size and hatching date without collecting corresponding data on individual condition (e.g. Hamann and Cooke 1987; Petersen 1992). To our knowledge, there is only one study that compares individual females between different years, finding a positive relation between Common Eider Somateria mollissima clutch size and female mass, but no relation with hatching date (Erikstad et al. 1993).

Egg size is another important component of parental effort in birds, and several studies have shown a positive relationship between egg size and offspring fitness, in altricial as well as precocial birds. Larger eggs may enhance offspring fitness by increasing survival prospects in the first days after hatching and competitive power through a larger offspring size and the possession of more resources to survive adverse conditions (Amundsen and Stokland 1990; Anderson and Alisauskas 2002; Ankney 1980; Christians 2002; Dawson and Clark 2000; Goth and Evans 2004; Magrath 1992; Potti 1999; Rutkowska and Cichon 2005). Increased egg size through food supplementation could be linked to improved hatchability of the egg, increased size at hatching, early growth and survival during the nestling stage (reviewed in Williams 1994; Christians 2002, see also Grindstaff et al. 2005).

We studied seasonal egg and clutch size decline and their relation to female body condition in a non-migratory waterfowl species, the Upland Goose Chloephaga picta leucoptera. Upland Geese belong to the order of the sheldgeese (Tadornini), a group that physically resembles true geese (Anserinae) and shows similar habits but is more closely related to shelducks and ducks. The smaller (migratory) sub-species $C$. picta picta breeds on the South American mainland, whereas the slightly larger one (C. picta leucoptera) is restricted to the Falkland Islands. Their basic breeding biology and life-cycle has been studied in the Falklands from 1977 to 1980 (Summers 1983). Upland geese are highly territorial and socially monogamous, usually returning to the same territory with the same mate every year. Territories are taken up from August onwards and eggs laid between late September and end of October. The mean clutch comprises 6 eggs (Summers and McAdam 1993). Hatching mainly takes place between mid-October and mid-November and fledging starts at about 70 days of age. No creching occurs during the breeding season, and family groups stay together for the austral summer and winter (Summers 1983).

Additionally to the general analysis of the relationship of clutch size, hatching date and body condition in this non-migratory waterfowl species, we were able to compare data from individual females captured in subsequent years in the same territories. To our knowledge, this is the first study on seasonal clutch size decline in sheldgeese, and one of a few comparing condition and timing of breeding within individuals between different years in waterfowl.

We tested the following hypotheses:

1. Egg and clutch size decrease with increasing hatching date.

2. Egg size, clutch size and hatching date is related to female body condition.

3. Individual variation in hatching dates is related to individual variation in body condition.

4. Chicks hatched from larger eggs are in a better condition than chicks from smaller eggs.

\section{Methods}

The study was carried out in the New Island Nature Reserve, Falkland Islands $\left(51^{\circ} 43^{\prime} \mathrm{S}, 61^{\circ} 17^{\prime} \mathrm{W}\right)$ from October to December in 2005, 2007 and 2008. New Island has an estimated $84 \mathrm{~km}$ of coastline embracing some 2,300 ha. The island has been established as a nature reserve in 1970 when all livestock was removed from the island. This led to an increase in the density of Upland Geese, which is now, 
with approximately 0.8 pairs ha ${ }^{-1}$, one of the highest in the Falkland Islands (Quillfeldt et al. 2005).

For the study of seasonal decline, a total of 84 nests were included in the analysis ( 29 from 2005, 25 from 2007 and 30 from 2008). At the start of each field season, we mapped nests using GPS. Females left their nests at varying distances when approached, eggs were covered with down after measurements and all females returned to their nests afterwards. For each nest, we determined clutch size, measured length ( $L$, expressed in $\mathrm{cm})$ and width $(B$, expressed in $\mathrm{cm}$ ) of each egg to the nearest $0.1 \mathrm{~mm}$ using callipers, and weighed each egg to the nearest $0.1 \mathrm{~g}$ using a digital balance. Egg volume $\left(V\right.$, in $\left.\mathrm{cm}^{3}\right)$ was calculated as $V=\left(L \times B^{2} \times 0.507\right)$ following Furness and Furness (1981). We defined total clutch volume as the sum of the volumes of each egg in the clutch. Avian eggs decrease in density with increasing length of incubation mainly due to water loss. In 2005, a subsample of eggs was reweighed at a later date to estimate the density loss. Eggs lost an average of $0.0063 \pm 0.0005 \mathrm{SE} \mathrm{g} / \mathrm{cm}^{3}$ per day. We determined expected hatching date as follows: (1) we calculated egg density $(D)$ from egg mass $M$ (expressed in g) and $V$; (2) our 2005 data showed that hatching occurred at a mean egg density of $0.89 \mathrm{~g} / \mathrm{cm}^{3} \pm 0.01 \mathrm{~g} / \mathrm{cm}^{3} \mathrm{SE}(n=14$ eggs), and (3) the number of days to hatching $T$ was thus estimated as $T=\left(D-0.89 \mathrm{~g} / \mathrm{cm}^{3}\right) / 0.0063 \mathrm{~g} / \mathrm{cm}^{3}$. We then visited nests again at least once a day, starting at the estimated hatching date. All eggs hatched within 0-2 days of the estimated hatch date.

We caught adults during the period when they attended their brood (mean chick age: $14.8 \pm 4.1$ days) using a $3 \times 5 \mathrm{~m}$ whoosh net. One person herded the family of geese slowly to the catching area, and when they arrived directly in front of the furled net, the other researcher pulled the trigger. Adults were marked with an individual metal ring on one leg and a plastic ring readable from a distance on the other, and weighed to the nearest $10 \mathrm{~g}$ using a digital spring balance. Head length, culmen length and tarsus length were measured to the nearest $0.1 \mathrm{~mm}$ using callipers, and wing length (maximum flattened chord) was measured to the nearest $1 \mathrm{~mm}$ using a foot rule. Chicks were marked individually using web-tags placed in the foot webs. We left enough space for the foot web to grow and did not observe any adverse effects on gosling growth. Chicks were weighed to the nearest $1 \mathrm{~g}$ using a spring balance $(<300 \mathrm{~g})$ or to the nearest $10 \mathrm{~g}$ using a digital spring balance $(>300 \mathrm{~g})$. We measured head length, culmen length, wing length and tarsus length $( \pm 0.1 \mathrm{~mm})$ using callipers. Chick age was determined from a growth curve for head and tarsus lengths established from chicks of known age in 2005. For each clutch, the mean chick age and thereby mean hatching date were calculated. As hatching dates could not be determined from egg density for all individual females, we used this estimated hatching date for further analyses. Estimated hatching dates from egg measures and chick measures were highly correlated $(R=0.973, P<0.001, n=41)$.

The body condition of females was then determined accounting for structural size and chick age, as we did not catch females during the prelaying period and captured females had goslings of different age. Females lose weight during incubation, and regain weight after hatching of the chicks (Summers and McAdam 1993). We estimated an expected body mass for each individual based on a multiple linear regression of body mass on the first principal component (PC1) of measurements of wing, head, bill and tarsus and chick age. Body condition was calculated as the ratio of the observed body mass to the derived expected body mass, according to female size and chick age. For the analysis of the effect of mean egg volume on chick body condition, we only included clutches with chicks $\leq 20$ days of age as until then no sex-specific growth was observed (A. Gladbach, unpublished data). Chick body condition was expressed as the ratio of observed to expected body mass. To avoid using the same data to determine chick body condition and chick age (see above), in this case we used the estimated hatching date determined from egg density data. Expected body mass was the population mean of chicks of the same age (based on body mass data of a total of 553 chicks), following Quillfeldt (2002). Using this method, age is included indirectly into the model and hence controlled for. As a result, body condition is by definition uncorrelated (orthogonal) to age. For each clutch, we calculated a mean body condition of chicks.

\section{Statistical analysis}

Statistical tests were performed in SPSS 11.0 and R 2.9.1 (R Development Core Team 2009, http://www.r-project.org). Normality was tested with Kolmogorov-Smirnov tests and data were transformed, if necessary. Means are given with standard errors. We assessed significance using Pearson correlations or $F$ statistics in General Linear Models (GLM), based on Type III Sum of Squares. To indicate the direction (positive or negative) of the correlation to the covariable, we included $t$ values, and as a measure of effect sizes, we included partial eta-squared values $\left(\eta^{2}\right)$ (i.e. the proportion of the effect + error variance that is attributable to the effect). The sums of the partial eta-squared values are not additive (e.g. http://web.uccs.edu/lbecker/SPSS/ glm_effectsize.htm). To analyse the dependency of mean egg volume on clutch size, we used a non-parametric Spearman correlation.

For the analysis of individual data from different years, we used a linear mixed effects model (lme) in R 2.9.1 with hatching date as the response variable, body condition and 
year (as ordered fixed factor) as explanatory variables and female identity as a random effect. In this way, we could simultaneously test whether hatching date on an individual basis depended on body condition or if there was a relation with increasing age (year). In the final model, "year" was excluded based on the stepwise AIC function, an information-theoretical approach (Burnham and Anderson 2004). We present here results of this final model.

Statistical repeatabilities of variables in different years were calculated by the method of Lessells and Boag (1987). Significance level was set to $P<0.05$. Some territories were not visited before chicks hatched and hence some data on clutch size and egg volumes were missing, resulting in different sample sizes for the respective tests.

\section{Results}

Egg and clutch size decline

Clutch size and mean egg volume were significantly higher in clutches with earlier hatching date (Fig. 1; Table 1). Mean egg volume increased significantly with increasing clutch size (Pearson correlation, $R=0.377, P<0.001$ ). This correlation remained significant when controlling for female structural size $(R=0.373, P=0.018)$, but not when controlling for female mass $(R=0.221, P=0.171)$ or body condition $(R=0.238, P=0.139)$.

Female body condition and hatching date, clutch size and mean egg volume

Hatching date and female post-hatching body condition were positively related, with females in a better body condition having earlier clutches (Fig. 2; Table 2).

We compared data of 28 recaptured individuals (5 captured in all three study years, 4 in 2005 and 2008, 4 in 2005 and 2007 and 15 individuals in 2007 and 2008). Body condition data showed significant repeatability $(r=0.308$, $F_{27,60}=1.969, \quad P=0.032$ ), whereas repeatability of hatching date was non-significant $\left(r=-0.171, F_{27,60}=\right.$ $0.683, P=0.844)$. Hatching date was significantly negatively related to body condition within individuals (lme in $R$; body condition: $F_{1,32}=18.80, t=-4.336, P \leq 0.001$ ), while changes in year (i.e. female age) did not systematically affect hatching date as it was dropped from the full model (see "Statistical analysis").

Clutch size and mean egg volume were higher in females in better post-hatching body condition and this relationship was independent of the sample year (Fig. 3; Table 2).

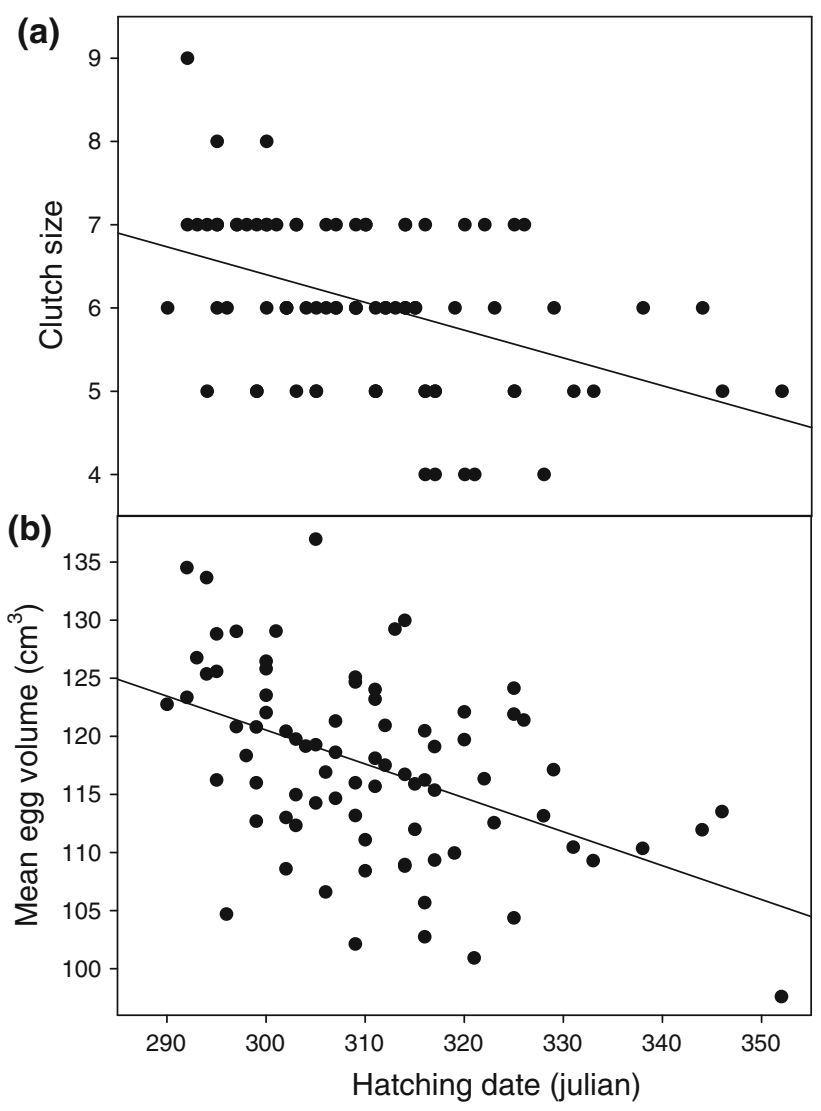

Fig. 1 Seasonal decline of clutch size (a), and mean egg volume (b) in Upland Geese Chloephaga picta leucoptera on New Island

Egg volume and chick body condition

Chick body condition was positively related to mean egg volume and negatively to hatching date, i.e. chicks hatched from nests with higher mean egg volume and earlier clutches had significantly higher early body condition (Table 3; Fig. 4). Clutch size had no effect on chick early body condition (Table 3 ). Mean body condition of chicks from females with high body condition was higher compared to chicks of low body condition females (Table 3).

\section{Discussion}

In our present study on Upland Geese we found that:

1. Clutch size and egg size decreased with later hatching date.

2. Clutch size variables and hatching date were related to female post-hatching body condition.

3. Individual variation in hatching dates was related to individual variation in body condition.

4. Egg size had a direct and positive effect on chick body condition in the first weeks after hatching. 
Table 1 Results of general linear models (GLM) showing the effects of year and hatching date on clutch size and mean egg volume in adult female Upland Geese Chloephaga picta leucoptera

\begin{tabular}{llcc}
\hline Parameter & Year & Hatching date $($ hd $)$ & Interaction $($ year $\times$ hd) \\
\hline Clutch size & $F_{2,84}=0.469, P=0.628$, & $F_{1,84}=13.213, \boldsymbol{P}<\mathbf{0 . 0 0 1}$, & $F_{2,84}=0.434, P=0.649$, \\
& $\eta^{2}=0.012$ & $\eta^{2}=0.145, t=-1.300$ & $\eta^{2}=0.011$ \\
Mean egg volume & $F_{2,84}=1.505, P=0.228$, & $F_{1,84}=20.183, \boldsymbol{P}<\mathbf{0 . 0 0 1 ,}$ & $F_{2,84}=1.528, P=0.223$, \\
& $\eta^{2}=0.037$ & $\eta^{2}=0.206, t=-1.273$ & $\eta^{2}=0.038$ \\
\hline
\end{tabular}

Clutch size or mean egg volume were used as dependent, year as a fixed factor and hatching date as covariate. $\eta^{2}$ was included to indicate the effect size and $t$ values to indicate the direction (positive or negative) of the correlation to the covariable. Significant $P$ values are shown in bold

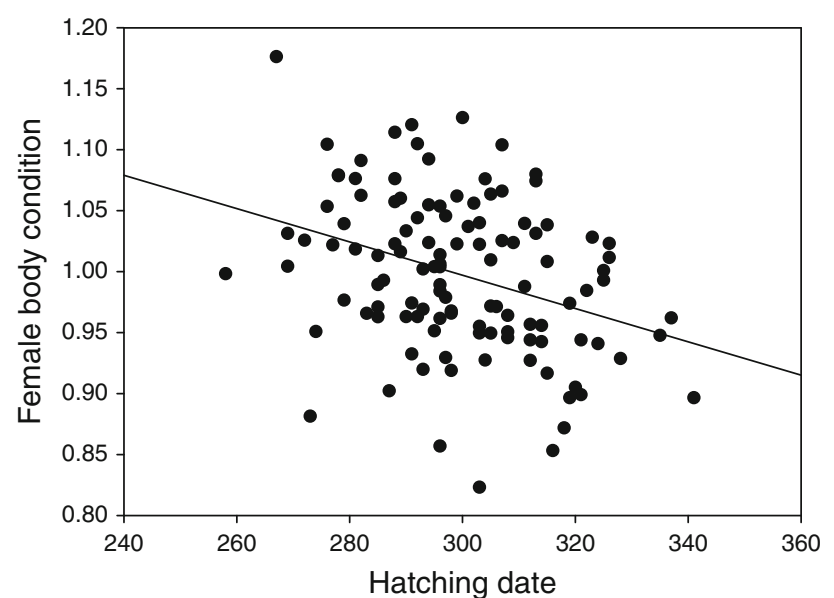

Fig. 2 Negative relationship between female body condition and hatching date in Upland Geese

We found the observed seasonal decline of clutch and egg size on the population level in Upland Geese to be mainly caused by the early onset of reproduction by females in good body condition. We could show, to our knowledge for the first time, that the commonly observed positive relation between female condition and hatching date also holds true on an individual basis. Annual variation in individual body condition had a direct effect on the onset of reproduction, with females in an individually better condition having earlier hatching dates. The significant repeatability of post-hatching body condition indicates that differences in quality between individuals remain stable over several years, but that despite this stability small individual changes in body condition affect timing of reproduction. However, as we did not measure female prebreeding condition, we are aware that our results must be treated cautiously as it may not necessarily be linked to her post-hatching condition, an assumption that still needs to be tested in Upland Geese.

Differences in body condition between individuals may arise due to differences in the inherent quality of individual birds (e.g. Jensen et al. 2003; e.g. Merila et al. 2001), which is supported by the significant repeatability of body condition in our study. As Upland Geese return to the same territories every year, also differences in territory quality may affect female body condition. Differences in individual body condition could have more immediate causes such as differences in weather, food availability, health state etc. That small differences in condition affect the timing of the onset of reproduction supports the idea that (1) egg laying starts when a certain individual threshold body condition is reached, and (2) that the investment into egg size and number decreases as the season advances, as expected offspring value is assumed to decline during a breeding season. Alternatively, if female-post-hatching condition is closely linked to her pre-laying condition, the investment into more and heavier eggs could also be explained by this better body condition. In contrast to previous studies that found an age effect with earlier hatching dates in older age classes to be the main cause for inter-individual variation in hatching dates (Blums et al. 2002; Finney and Cooke 1978;

Table 2 Results of general linear models (GLM) showing the effects of year and body condition on hatching date, clutch size and mean egg volume in adult female Upland Geese

\begin{tabular}{lccc}
\hline Parameter & Year & Body condition $(\mathrm{bc})$ & Interaction $($ year $\times$ bc $)$ \\
\hline Hatching date & $F_{2,83}=0.301, P=0.741$, & $F_{1,83}=10.138, \boldsymbol{P}=\mathbf{0 . 0 0 2}$, & $F_{2,83}=0.303, P=0.739$, \\
& $\eta^{2}=0.008$ & $\eta^{2}=0.116, t=-1.199$ & $\eta^{2}=0.008$ \\
Clutch size & $F_{2,41}=1.314, P=0.282$, & $F_{1,41}=10.741, \boldsymbol{P}=\mathbf{0 . 0 0 2}$, & $F_{2,41}=1.119, P=0.338$, \\
& $\eta^{2}=0.070$ & $\eta^{2}=0.235, t=3.174$ & $\eta^{2}=0.060$ \\
Mean egg volume & $F_{2,39}=0.356, P=0.703$, & $F_{1,39}=15.366, \boldsymbol{P}<\mathbf{0 . 0 0 1}$, & $F_{2,39}=0.503, P=0.609$, \\
& $\eta^{2}=0.021$ & $\eta^{2}=0.318, t=2.085$ & $\eta^{2}=0.030$
\end{tabular}

Hatching date, clutch size or mean egg volume were used as dependent, year as a fixed factor and hatching date as covariate. $\eta^{2}$ was included to indicate the effect size and $t$ values to indicate the direction (positive or negative) of the correlation to the covariable. Significant $P$ values are shown in bold 


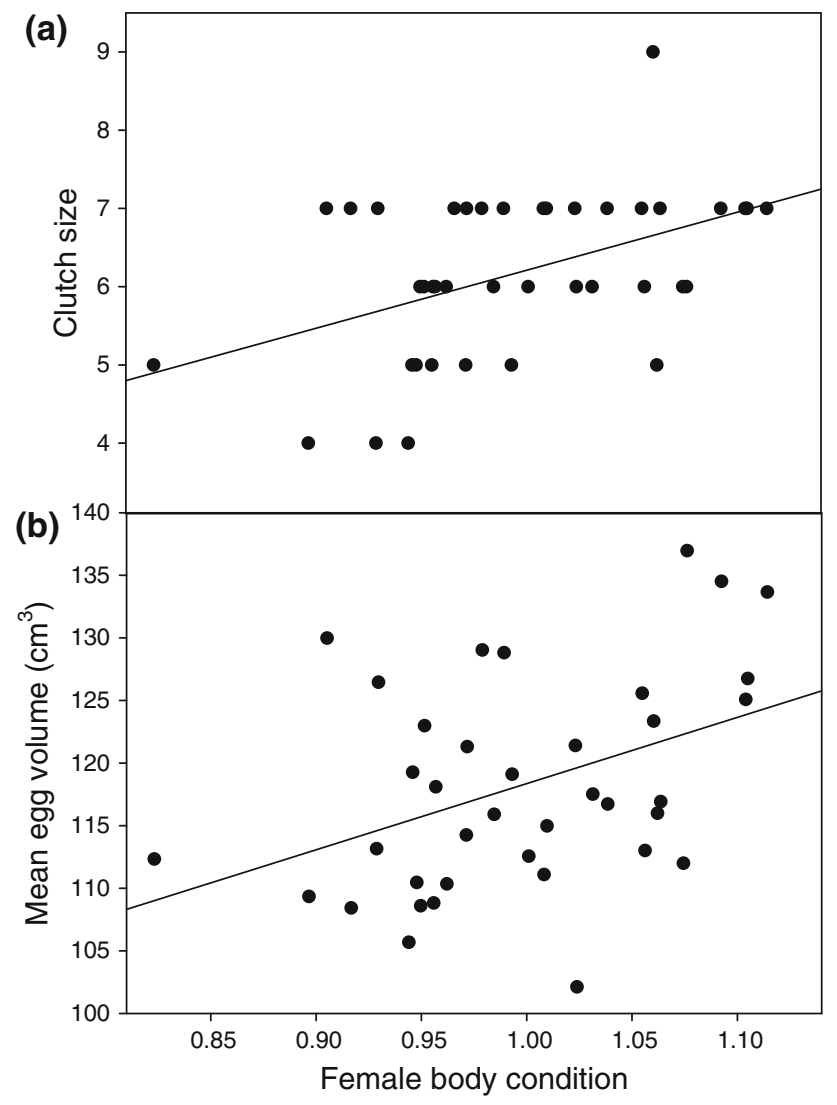

Fig. 3 Positive relationship between female body condition and clutch size (a), and mean egg volume (b) in Upland Geese on New Island

Hamann and Cooke 1987, 1989), we did not observe a decline in hatching date within individual females over the study years. Upland Geese have an average adult life expectancy of about 5 years (Summers and McAdam 1993),so our study period covered a considerable amount of this expected lifespan. However, the small sample size

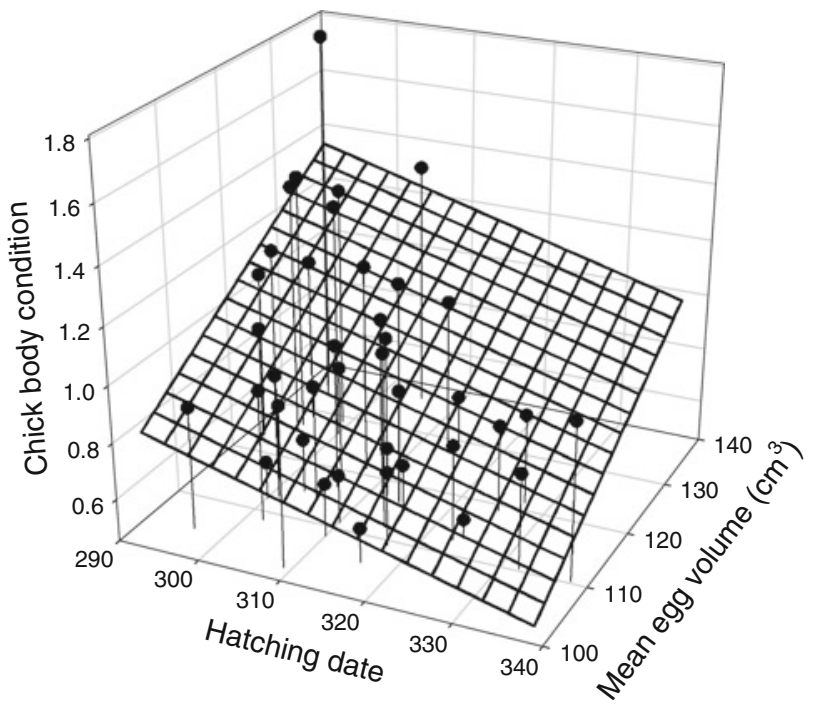

Fig. 4 Relationship between chick body condition, hatching date and mean egg volume in Upland Geese

of individuals sampled in three different years $(n=5)$ may also explain why we could not detect an age effect in our study. One hint of the possibility of an age effect at the very end of an individual life span is one female found dead at the end of the last study year which had hatched chicks 30 days earlier in 2008 than in 2005 and 2007.

In precocial species like waterfowl, where the young feed for themselves after hatching, the role of the parents and their effect on offspring performance is harder to detect than in altricial species. Parental quality may not only be reflected in the effect of social factors like predator avoidance/defence and social competence for variation of reproductive success. High quality parents may also be able to produce larger clutches and to accumulate more resources more rapidly than low quality individuals which

Table 3 Results of general linear models (GLM) showing the effects of year, hatching date and $(A)$ mean egg volume, $(B)$ clutch size and $(C)$ female body condition on early chick body condition in Upland Geese

\begin{tabular}{lll}
\hline A & Year & $F_{2,39}=0.844, P=0.439, \eta^{2}=0.047$ \\
& Hatching date & $F_{1,39}=4.582, \boldsymbol{P}=\mathbf{0 . 0 4 0}, \eta^{2}=0.119, t=-2.141$ \\
& Mean egg volume & $F_{1,39}=12.904, \boldsymbol{P}=\mathbf{0 . 0 0 1}, \eta^{2}=0.275, t=3.592$ \\
B & Year & $F_{2,39}=0.022, P=0.978, \eta^{2}=0.001$ \\
& Hatching date & $F_{1,39}=5.547, \boldsymbol{P}=\mathbf{0 . 0 2 4}, \eta^{2}=0.140, t=-2.355$ \\
Clutch size & $F_{1,39}=4.023, P=0.053, \eta^{2}=0.106, t=2.006$ \\
Year & $F_{2,39}=2.802, P=0.075, \eta^{2}=0.141$ \\
& Hatching date & $F_{1,39}=3.531, P=0.069, \eta^{2}=0.094, t=-1.879$ \\
& Female body condition & $F_{1,39}=2.597, \boldsymbol{P}<\mathbf{0 . 0 0 1}, \eta^{2} 535=0.420, t=4.960$
\end{tabular}

Chick body condition was used as dependent, year as a fixed factor and hatching date and mean egg volume, clutch size or female body condition as covariates. $\eta^{2}$ was included to indicate the effect size and $t$ values to indicate the direction (positive or negative) of the correlation to the covariable. Significant $P$ values are shown in bold 
would allow an earlier nesting (Drent and Daan 1980) and thereby providing better growing conditions for the offspring (Hoekman et al. 2004; Lepage et al. 1998, 1999). Female egg investment may play an important role in determining survival prospects of offspring (Amat et al. 2001) and thereby increasing individual fitness. We here show that early chick body condition increased with increasing egg size. This is line with other studies on waterfowl, where chick body size was also found to be related to egg size (e.g. Christians 2002; Ankney 1980; Anderson and Alisauskas 2002).

Interestingly, we found that egg size increased with increasing clutch size. Other studies on waterfowl have already shown that the theoretical trade-off between size and number of offspring as proposed by Lack (1968) can be observed on an interspecific level (Figuerola and Green 2006), but is not always present on an intraspecific level (Christians 2000; see Christians 2002 for a review). The intraspecific relationship does not show a consistent pattern, as there was no correlation between egg size and clutch size in some species but a positive correlation in others (see Christians 2002 for a review). Hõrák et al. (2008) pointed out that the absence of a trade-off between egg size and number may be explained by the lower quality of young hatched from larger clutches, i.e. the trade-off occurring between egg number and hatchling quality. We found no evidence that this is true for Upland Geese, as clutch size had no influence on chick body condition.

Flint et al. (1996) suggested that, in waterfowl which rely on endogenous reserves for egg production, largebodied birds may tend to lay larger clutches of larger eggs than do small-bodied birds. Our results show that in Upland Geese body size is no proxy for egg size as we failed to detect a relationship between structural size and either egg or clutch size. In contrast, the availability of endogenous reserves (reflected in body mass and body condition) was an important source for variation in egg and clutch size between female Upland Geese. This supports the idea that high-quality females are able to produce more and larger eggs than low-quality females, although we could not distinguish whether the higher body condition of these females was caused by higher foraging efficiency, or indirectly by defending a high-quality territory. Assessing the body condition during the non-breeding season, when Upland Geese gather in large groups around ponds, could shed further light on the importance of the breeding territory or winter condition for the differences in body condition during the breeding season. In addition, a comparison of individual clutch and egg size measures in relation to body condition over several years, which was not possible in this study, could further deepen our understanding of optimal investment.

\section{Zusammenfassung}

Saisonaler Rückgang der Gelegegröße und individuelle Variation des Brutgbeginns sind bei der nicht-ziehenden Magellangans Chloephaga picta leucoptera von der weiblichen Körperkondition abhängig

Viele Studien an Wasservögeln haben gezeigt, dass Weibchen in guter Kondition größere Gelege haben und früher in der Brutsaison mit der Eiablage beginnen. Allerdings fehlen in diesen Studien parallele Daten über individuelle Kondition und Brutbeginn in verschiedenen Jahren. Wir haben Daten über die Gelege- und Eigröße, das Schlupfdatum und die Körperkondition der Weibchen bei der Magellangans Chloephaga picta leucoptera während dreier Brutsaisons auf New Island, Falklandinseln, aufgenommen und untersucht, inwieweit Variabilität von Reproduktionsparametern und Körperkondition sowohl innerhalb als auch zwischen Weibchen zusammenhängen.

Wir fanden eine starke saisonale Abnahme von sowohl Ei- als auch Gelegegröße auf Populationsebene. Ei- und Gelegegröße nahmen mit steigender Weibchenkondition zu und Weibchen in besserer Körperkondition hatten frühere Gelege. Küken aus Gelegen mit größeren Eiern waren in einer besseren Körperkondition. Der Vergleich individueller Daten aus verschiedenen Jahren ergab dass die Körperkondition zwischen den Jahren signifikant wiederholbar war, das Schlupfdatum jedoch nicht. Während Unterschiede im Alter der Weibchen keinen Effekt auf das Schlupfdatum hatten, ging eine individuelle Verbesserung der Kondition mit einem früheren Schlupfdatum einher. Wir konnten damit zum ersten Mal zeigen, dass der bekannte allgemeine Zusammenhang von Körperkondition der Weibchen und Reproduktionszeitpunkt auch auf individueller Ebene Gültigkeit besitzt. Unserem Wissen nach ist dies die erste Studie zu saisonaler Gelegeverkleinerung bei Halbgänsen und eine von wenigen an Wasservögeln die Körperkondition und Reproduktionszeitpunkt innerhalb von Individuen und zwischen verschiedenen Jahren vergleicht.

Acknowledgments We are grateful to the New Island Conservation Trust for the possibility to carry out this study on the island and for providing accommodation and transport. We would like to thank Riek van Noordwijk, Rafael Matias and Andreas Michalik for their help in capturing "difficult" goose families. The manuscript benefited from the comments of two anonymous referees, and Yann Clough checked the English. This work would not have been possible without the support of Ian, Maria and Georgina Strange and Dan Birch. A.G. received financial support by the Bayerische Eliteförderung, the Arthur-von-Gwinner-Foundation, the German Academic Exchange Service (DAAD) and the German Ornithological Society (DO-G). P.Q. was funded by DFG, Germany (Emmy Noether Programme, Qu148/1-3). 
Open Access This article is distributed under the terms of the Creative Commons Attribution Noncommercial License which permits any noncommercial use, distribution, and reproduction in any medium, provided the original author(s) and source are credited.

\section{References}

Amat JA, Fraga RM, Arroyo GM (2001) Intraclutch egg-size variation and offspring survival in the Kentish plover Charadrius alexandrinus. Ibis 143:17-23

Amundsen T, Stokland JN (1990) Egg size and parental quality influence nestling growth in the shag. Auk 107:410-413

Anderson VR, Alisauskas RT (2002) Composition and growth of king eider ducklings in relation to egg size. Auk 119:62-70

Ankney CD (1980) Egg weight, survival, and growth of lesser snow goose goslings. J Wildl Manage 44:174-182

Bengston SA (1971) Variations in clutch-size in ducks in relation to the food supply. Ibis 113:523-526

Bety J, Gauthier G, Giroux JF (2003) Body condition, migration, and timing of reproduction in snow geese: a test of the conditiondependent model of optimal clutch size. Am Nat 162:110-121

Blums P, Clark RG, Mednis A (2002) Patterns of reproductive effort and success in birds: path analyses of long-term data from European ducks. J Anim Ecol 71:280-295

Burnham KP, Anderson DR (2004) Model selection and multi-model inference: a practical information-theoretic approach. Springer, Berlin

Christians JK (2000) Trade-offs between egg size and number in waterfowl: an interspecific test of the van Noordwijk and de Jong model. Funct Ecol 14:497-501

Christians JK (2002) Avian egg size: variation within species and inflexibility within individuals. Biol Rev 77:1-26

Dalhaug L, Tombre IM, Erikstad KE (1996) Seasonal decline in clutch size of the barnacle goose in Svalbard. Condor 98:42-47

Dawson RD, Clark RG (2000) Effects of hatching date and egg size on growth, recruitment, and adult size of lesser scaup. Condor 102:930-935

Devries JH, Brook RW, Howerter DW, Anderson MG (2008) Effects of spring body condition and age on reproduction in mallards (Anas platyrhynchos). Auk 125:618-628

Drent RH, Daan S (1980) The prudent parent-energetic adjustments in avian breeding. Ardea 68:225-252

Erikstad KE, Bustnes JO, Moum T (1993) Clutch-size determination in precocial birds - a study of the common eider. Auk 110:623628

Figuerola J, Green AJ (2006) A comparative study of egg mass and clutch size in the Anseriformes. J Ornithol 147:57-68

Finney G, Cooke F (1978) Reproductive habits in snow gooseinfluence of female age. Condor 80:147-158

Flint PL, Grand JB, Sedinger JS (1996) Allocation of limited reserves to a clutch: a model explaining the lack of a relationship between clutch size and egg size. Auk 113:939-942

Furness RW, Furness BL (1981) A technique for estimating the hatching dates of eggs of unknown laying date. Ibis 123:98-102

Goth A, Evans CS (2004) Egg size predicts motor performance and postnatal weight gain of Australian brush-turkey (Alectura lathami) hatchlings. Can J Zool-Rev Can Zool 82:972-979

Grindstaff JL, Demas GE, Ketterson ED (2005) Diet quality affects egg size and number but does notreduce maternal antibody transmission in Japanese quail Coturnix japonica. J AnimEcol 74:1051-1058

Hamann J, Cooke F (1987) Age effects on clutch size and laying dates of individual female lesser snow geese Anser caerulescens. Ibis 129:527-532
Hamann J, Cooke F (1989) Intra-seasonal decline of clutch size in lesser snow geesee. Oecologia 79:83-90

Hochachka W (1990) Seasonal decline in reproductive performance of song sparrows. Ecology 71:1279-1288

Hoekman ST, Gabor TS, Maher R, Murkin HR, Armstrong LM (2004) Factors affecting survival of mallard ducklings in southern Ontario. Condor 106:485-495

Hõrák D, Klvana P, Albrecht T (2008) Why there is no negative correlation between egg size and number in the common pochard? Acta Oecol 33:197-202

Jensen H, Saether BE, Ringsby TH, Tufto J, Griffith SC, Ellegren H (2003) Sexual variation in heritability and genetic correlations of morphological traits in house sparrow (Passer domesticus). J Evol Biol 16:1296-1307

Johnsgard PA (1973) Proximate and ultimate determinants of clutch size in Anatidae. Wildfowl 24:144-149

Karell P, Kontiainen P, Pietiainen H, Siitari H, Brommer JE (2008) Maternal effects on offspring Igs and egg size in relation to natural and experimentally improved food supply. Funct Ecol 22:682-690

Klomp H (1970) Determination of clutch-size in birds. A review. Ardea 58:1-124

Lack D (1968) Ecological adaptations for breeding in birds. Methuen, London

Lamprecht J (1985) Dominance and reproductive success in barheaded Geese (Anser indicus): a multiple-regression analysis. JOrnithol 126:287-293

Lepage D, Gauthier G, Reed A (1998) Seasonal variation in growth of greater snow goose goslings: the role of food supply. Oecologia 114:226-235

Lepage D, Desrochers A, Gauthier G (1999) Seasonal decline of growth and fledging success in snow geese, Anser caerulescens: an effect of date or parental quality? J Avian Biol 30:72-78

Lessells CM, Boag PT (1987) Unrepeatable repeatabilities-a common mistake. Auk 104:116-121

Magrath R (1992) The effect of egg mass on the growth and survival of blackbirds: a field experiment. J Zool Lond 227:639-653

Meijer T, Daan S, Dijkstra C (1988) Female condition and reproduction-effects of food manipulation in free-living and captive kestrels. Ardea 76:141-154

Meijer T, Daan S, Hall M (1990) Family-planning in the kestrel (Falco tinnunculus) - the proximate control of covariation of laying date and clutch size. Behaviour 114:117-136

Merila J, Kruuk LEB, Sheldon BC (2001) Natural selection on the genetical component of variance in body condition in a wild bird population. J Evol Biol 14:918-929

Owen M, Black JM (1990) Waterfowl ecology. Blackie, Glasgow

Petersen MR (1992) Reproductive ecology of emperor geese-annual and individual variation in nesting. Condor 94:383-397

Potti J (1999) Maternal effects and the pervasive impact of nestling history on egg size in a passerine bird. Evolution 53:279-285

Quillfeldt P (2002) Begging in the absence of sibling competition in Wilson's storm-petrels, Oceanites oceanicus. Anim Behav 64:579-587

Quillfeldt P, Strange IJ, Masello JF (2005) Escape decisions of incubating females and sex ratio of juveniles in the upland goose Chloephaga picta. Ardea 93:171-178

Rowe L, Ludwig D, Schluter D (1994) Time, condition, and the seasonal decline of avian clutch size. Am Nat 143:698-772

Rutkowska J, Cichon M (2005) Egg size, offspring sex and hatching asynchrony in zebra finches Taeniopygia guttata. J Avian Biol 36:12-17

Ryder JP (1970) A possible factor in the evolution of clutch size in Ross' goose. Wilson Bull 82:5-13

Schindler M, Lamprecht J (1987) Increase of parental effort with brood size in a nidifugous bird. Auk 104:688-693 
Sjoberg G (1994) Early breeding leads to intra-seasonal clutch size decline in Canada geese. J Avian Biol 25:112-118

Sockman KW, Sharp PJ, Schwabl H (2006) Orchestration of avian reproductive effort: an integration of the ultimate and proximate bases for flexibility in clutch size, incubation behaviour, and yolk androgen deposition. Biol Rev 81:629-666

Summers RW (1983) The life-cycle of the upland goose (Chloephaga picta) in the Falkland-Islands. Ibis 125:524-544
Summers RW, McAdam JH (1993) The upland goose. Bluntisham Books, Huntingdon

Williams TD (1994) Intraspecific variation in egg size and egg composition in birds: effects on offspring fitness. Biol Rev Camb Philos Soc 69:35-59

Winkler DW, Walters JR (1983) The determination of clutch size in precocial birds. Curr Ornithol 1:33-68 